\title{
Glucose Variability is Independently Correlated with Serum Level of Pigment Epithelium-Derived Factor in Type 2 Diabetes
}

\author{
Tomoki Fujikawa · Makoto Ohara (D) - Yo Kohata · Hiroe Nagaike · Ayako Fukase • \\ Naoya Osaka · Hironori Yashima • Nobuko Sato · Hideki Kushima • Kyoko Shinmura • \\ Yasuyoshi Takahashi · Munenori Hiromura · Michishige Terasaki · Yusaku Mori · \\ Tomoyasu Fukui · Takanori Matsui · Tsutomu Hirano · Sho-ichi Yamagishi
}

Received: December 12, 2020 / Accepted: January 20, 2021 / Published online: February 13, 2021

(C) The Author(s) 2021

\section{ABSTRACT}

Introduction: Pigment epithelium-derived factor (PEDF) may play a role in cardiometabolic disorders. The aim of this study was to investigate which biochemical and clinical parameters are independently associated with serum PEDF levels in patients with type 2 diabetes mellitus (T2DM).

Methods: We performed a cross-sectional analysis of 124 patients with T2DM who underwent continuous glucose monitoring (CGM) and

T. Fujikawa $\cdot$ M. Ohara $(\varangle) \cdot$ Y. Kohata .

H. Nagaike · A. Fukase · N. Osaka · H. Yashima .

N. Sato · H. Kushima - K. Shinmura - Y. Takahashi ·

M. Hiromura · M. Terasaki · T. Fukui · T. Hirano ·

S. Yamagishi

Division of Diabetes, Metabolism, and

Endocrinology, Department of Medicine, Showa

University School of Medicine, Tokyo, Japan

e-mail: s6018@nms.ac.jp

Y. Mori

Anti-Glycation Research Section, Division of Diabetes, Metabolism, and Endocrinology,

Department of Medicine, Showa University School

of Medicine, Tokyo, Japan

T. Matsui

Department of Pathophysiology and Therapeutics of Diabetic Vascular Complications, Kurume

University School of Medicine, Kurume, Japan

T. Hirano

Diabetes Center, Ebina General Hospital, Ebina, Japan blood chemistry analysis, including the diacron-reactive oxygen metabolites (d-ROMs) test and serum PEDF measurement (study 1 ). Then we investigated whether the changes in the studied biochemical and clinical parameters after 24 weeks of treatment ( $\Delta$ parameters) with anti-hyperglycemic agents, including sodiumglucose cotransporter 2 inhibitors, glucagonlike peptide 1 receptor agonists, and/or insulin and anti-hypertensive drugs and statins, were independently correlated with change in PEDF ( $\triangle \mathrm{PEDF}$ ) in 52 of the patients with T2DM for whom there was sufficient serum samples to perform the post-treatment analysis (study 2). Serum levels of PEDF were measured with an enzyme-linked immunosorbent assay. CGM metrics were calculated on days 2 and 3 . Oxidative stress was evaluated using the d-ROMs test.

Results: Body mass index (BMI), triglycerides, fasting C-peptide, mean amplitude of glycemic excursions (MAGE), urinary albumin-to-creatinine ratio (UACR), and d-ROMs were positively associated with serum PEDF level, and high-density lipoprotein cholesterol (HDL-C) and estimated glomerular filtration rate (eGFR) were inversely associated with serum PEDF level. Because these parameters were correlated with each other, multivariate stepwise analysis was performed: eGFR, HDL-C, BMI, MAGE, and UACR remained significant $\left(R^{2}=0.452\right)$. Furthermore, $\triangle$ MAGE and $\triangle \mathrm{d}$-ROMs were positively correlated with $\triangle \mathrm{PEDF}$ in study 2 . 
Conclusions: The results of this study suggest that MAGE may be independently correlated with elevations in serum PEDF level in patients with T2DM.

Keywords: Cardiovascular disease; Continuous glucose monitoring; Glucose variability; Oxidative stress; pigment epithelium-derived factor; Type 2 diabetes mellitus

\section{Key Summary Points}

Why carry out this study?

Pigment epithelium-derived factor (PEDF) may play a role in cardiometabolic disorders.

Therefore, we investigated which biochemical and clinical parameters are independently associated with serum PEDF levels in patients with type 2 diabetes mellitus (T2DM).

In addition, we investigated the relationship between the change in serum PEDF levels and the change in various biochemical and clinical parameters, including glucose variability, in patients with T2DM who underwent treatment (intervention) for 24 weeks.

\section{What was learned from the study?}

Serum levels of PEDF may be elevated as a counter-system against glucose variability-induced oxidative stress generation in patients with T2DM.

The clinical association between serum levels of PEDF and atherosclerotic cardiovascular disease may be partly ascribed to elevated glucose variability in patients with T2DM.

\section{DIGITAL FEATURES}

This article is published with digital features, including a summary slide, to facilitate understanding of the article. To view digital features for this article go to https://doi.org/10.6084/ m9.figshare.13607435.

\section{INTRODUCTION}

Pigment epithelium-derived factor (PEDF) was first identified from culture media of human retinal pigment epithelium as a neuronal differentiating factor $[1,2]$ and then found to be one of the most potent endogenous anti-angiogenic factors in humans, involved in the development and progression of pathological angiogenesis-related disorders, such as proliferative diabetic retinopathy and various types of cancer $[3,4]$. PEDF has recently been shown to be secreted mainly from adipocytes and liver $[5,6]$ and to play an important role in the maintenance of tissue homeostasis by acting as an anti-inflammatory, anti-oxidative, and antithrombotic factor [7-9]. In addition, a number of research groups, including our own, have found that circulating levels of PEDF are increased in proportion to the number of components of metabolic syndrome [10] and that it is a biomarker of insulin resistance and central obesity in patients with type 2 diabetes mellitus (T2DM) [11-13]. PEDF is associated with obesity-induced insulin resistance, as demonstrated in a hyperinsulinemic-euglycemic clamp study [14], as well as with insulin resistance among individuals without diabetes $[15,16]$. Expression of PEDF is manipulated by beta-adrenergic receptor stimulation [17], suggesting the possibility that PEDF could play a role in sympathetic nerve activity [18]. In addition, circulating PEDF levels are associated with the presence of atherosclerotic cardiovascular disease and/or chronic kidney disease [19-21]. However, it is not yet fully understood which biochemical and clinical parameters related to cardiovascular events, including urinary albumin-to-creatinine ratio (UACR), an estimated glomerular filtration rate (eGFR), oxidative stress, and various markers of glucose variability evaluated by 
continuous glucose monitoring (CGM), are related to PEDF levels.

Glycated hemoglobin (HbA1c), a marker of average glucose levels over the past few months, is still the gold standard for the assessment of diabetes treatment [22]. However, HbA1c values do not necessarily reflect glucose variability and could be confounded by factors other than the average glucose level, such as anemia and renal impairment [22]. To overcome the limitations of HbA1c as a biomarker of diabetic complications, CGM technology has gained wide acceptance in the management of diabetic patients because it provides comprehensive information on the glucose profile $[22,23]$. Indeed, CGM systems can assess not only mean glucose levels (MGL), but also time above range (TAR; \% of readings and time $>180 \mathrm{mg} / \mathrm{dL}$ ), time below range (TBR; \% of readings and time $<70 \mathrm{mg} /$ $\mathrm{dL}$ ), time in range (TIR; \% of readings and time in range $70-180 \mathrm{mg} / \mathrm{dL}$ ), mean amplitude of glycemic excursions (MAGE), and mean of daily differences (MODD), all markers of daily and day-to-day glucose variability, respectively $[22,23]$.

In this study, we investigated which biochemical and clinical parameters, including various CGM metrics and oxidative stress levels evaluated by the diacron-reactive oxygen metabolites (d-ROMs) test [24], are independently associated with serum PEDF levels in T2DM patients. To this end, we first examined the independent correlates of serum levels of PEDF in 124 patients with T2DM (study 1). Then we investigated whether the changes in these parameters after 24 weeks of treatment ( $\Delta$ parameters) with oral hypoglycemic agents, including sodium-glucose cotransporter 2 inhibitors, glucagon-like peptide 1 receptor agonists, and/or insulin and sympathetic agents, wee independently correlated with change in PEDF levels $(\triangle \mathrm{PEDF})$ in $52 \mathrm{~T} 2 \mathrm{DM}$ patients for whom sufficient serum samples were available to perform the post-treatment analysis (study 2).

\section{METHODS}

\section{Design and Subjects of Study 1}

We performed a retrospective cross-sectional analysis of 124 patients with T2DM aged $>20$ years who visited Showa University Hospital from October 2013 to February 2018 for the treatment of T2DM. Patients who had been on stable anti-diabetic medications for at least 3 months were enrolled in the study. Exclusion criteria were: use of steroids or antiinflammatory drugs, diabetic ketosis and coma within the 3 months preceding the study; severe infection; severe trauma; malignancy; eGFR $<30 \mathrm{~mL} / \mathrm{min} / 1.73 \mathrm{~m}^{2}$ according to the Cockcroft-Gault formula [25]; pre- and postsurgery period; severe liver dysfunction; and pregnancy. All enrolled patients underwent CGM and blood chemistry analysis, including the d-ROMs test and measurement of serum PEDF (study 1). This study complies with the principles laid in the Declaration of Helsinki.

The study protocol was approved by the ethics committee of the Showa University School of Medicine (permission no. 3099). Informed consent was obtained from all individual participants included in the study by the opt-out method, as shown on our hospital website and the poster at Showa University Hospital. Subjects could opt out of the study at any time.

\section{Design and Subjects of Study 2}

Study 2 was a subanalysis of study 1 with the aim to assess which changes in clinical $(\Delta$ clinical) and biochemical parameters ( $\Delta$ biochemical parameters) were independently correlated with $\triangle$ PEDF in the 52 patients with T2DM for whom sufficient serum was available to perform the post-treatment analysis (study 2). Sample selection was not arbitrary, but study 2 subjects did not have completely equivalent baseline phenotypes as those of study 1 . The treatment programs were as follows. First, patients' glycemic control was assessed by several medical doctors with different treatment plans at one clinical center to achieve the following 
treatment targets, associated with the preventing the development of vascular complications, as defined by the Japan Diabetes Society, using the CGM data [26]: fasting plasma glucose (FPG) $<130 \mathrm{mg} / \mathrm{dL}, \quad 2$-h postprandial glucose (PPG) $<180 \mathrm{mg} / \mathrm{dL}$, and an HbA1c level of $<$ $7.0 \%(53 \mathrm{mmol} / \mathrm{mol})$. After 24 weeks of treatment, all patients underwent CGM and blood chemistry analysis, including the d-ROMs test and measurement of serum PEDF. All patients had high drug adherence during the study periods.

\section{CGM Systems}

The CGM sensor (CGMS System Gold; Medtronic MiniMed, Northridge, CA, USA or ipro2; Medtronic MiniMed) was inserted subcutaneously on day 1 and removed on day 4 , and CGM metrics were calculated on days 2 and 3 to avoid measurement bias. Blood samples were drawn with patients in the fasting condition, before breakfast and CGM insertion for biochemical analysis, including measurement of d-ROMs and PEDF, on day 1. All patients received a weight-maintaining diet $(25-30 \mathrm{kcal} /$ $\mathrm{kg}$ ideal body weight: 50-60\% carbohydrates, $20 \%$ proteins, and the rest fat). MAGE was calculated using the GlyCulator [27] in order to evaluate the daily glucose variability. MGL was measured from the data recorded during the CGM and was adjusted for self-monitored blood glucose. The coefficient of variation percentage (\%CV) was measured by dividing the standard deviation (SD) by MGL and multiplying by 100 [28]. MODD was calculated as the mean of the absolute difference between corresponding glucose values on days 2 and 3. TIR was defined as the percentage of time spent within target range of $70-180 \mathrm{mg} / \mathrm{dL}$ during a $24-\mathrm{h}$ period, while TAR and TBR were defined as time spent at $>180 \mathrm{mg} / \mathrm{dL}$ and $<70 \mathrm{mg} / \mathrm{dL}$, respectively.

\section{Laboratory Measurements}

Serum PEDF measurements were performed with the competitive enzyme-linked immunosorbent assay (ELISA) as described previously $[10,29]$. In brief, inter-assay and intra- assay coefficients of variation of the ELISA were 4.7 and $7.3 \%$, respectively. Recovery of the added recombinant PEDF in serum was $94.2 \pm 1.7 \%$. The assay linearity was shown to be intact with serial dilution of serum. We confirmed that concentrations of serum PEDF were similar to those of platelet-poor plasma and that PEDF was actually present in such high levels with western blots $[10,29]$. Oxidative stress was measured using the d-ROMs test (F.R.E.E. System, imported by LTD Tokyo from Diacron International s.r.l., Grosseto, Italy) as previously described $[24,28]$. In accordance with the Wismerll kinetic procedure, the change in absorbance per minute was expressed as arbitrary units after correction (U.CARR, where 1 U.CARR = the oxidant capacity of a $0.08 \mathrm{mg} / \mathrm{dL} \quad \mathrm{H}_{2} \mathrm{O}_{2}$ solution; normal range 250-300 U.CARR). Insulin resistance was evaluated by the serum C-peptide immunoreactivity insulin resistance (CPR-IR) index. CPRIR was calculated as 1080/[fasting-CPR (ng/ $\mathrm{mL}) \times \mathrm{FPG}(\mathrm{mg} / \mathrm{dL})]$ [30]. Other clinical and biochemical variables, such as HbA1c, FPG, total cholesterol, low-density lipoprotein-cholesterol (LDL-C), high-density lipoprotein-cholesterol (HDL-C), triglycerides (TG), creatinine levels, and UACR were measured as described previously [31].

\section{Statistical Analysis}

Data are presented as mean \pm SD. Simple linear correlations were calculated by determining Spearman's correlation coefficient because of non-normal distribution of data. Multiple stepwise regression analysis was then performed with PEDF as a dependent variable. Independent variables included body mass index (BMI), HDL-C, TG, eGFR, fasting C-peptide, CPR-IR, MAGE, UACR, use of calcium channel blockers, sodium-glucose cotransporter 2 inhibitors, and d-ROMs. In study 2, comparisons of clinical and biochemical variables between baseline and after 24 weeks of treatment were performed using the paired Student's $t$ test. Analyses were performed using IBM SPSS, version 22, for Windows (IBM Corp, Armonk, NY, USA) with a 
$p$ value of $<0.05$ indicating statistical significance.

\section{RESULTS}

\section{Clinical Characteristics of Patients in Study 1}

Baseline clinical characteristics of the 124 patients with T2DM patients enrolled in study 1 are shown in Table 1 . Mean $( \pm$ SD) age, mean diabetes duration, and mean HbA1c level of these patients were $64.2 \pm 12.5$ years, $13.5 \pm 11.4$ years, and $8.3 \pm 1.6 \%$, respectively. Of these patients, $84(67.7 \%)$ had hypertension and $94(75.8 \%)$ had dyslipidemia. Serum levels of PEDF were $7.5 \pm 1.8 \mu \mathrm{g} / \mathrm{mL}$. BMI, MGL, $\% \mathrm{CV}$, MAGE, TIR, and d-ROMs were $26.0 \pm 4.6 \mathrm{~kg} / \mathrm{m}^{2}, \quad 171.1 \pm 42.9 \mathrm{mg} / \mathrm{dL}, \quad 23.5 \pm$ $6.2 \%, 117.5 \pm 37.9 \mathrm{mg} / \mathrm{dL}, 60.6 \pm 29.3 \%$, and $344.6 \pm 60.9$ U.CARR, respectively.

\section{Relationship Between Serum PEDF and Laboratory Variables}

The correlations between serum levels of PEDF and the clinical and biochemical variables assessed are shown in Table 2. Significant correlations were observed between serum levels of PEDF and BMI, HDL-C, TG, eGFR, fasting C-peptide, CPR-IR, MAGE, UACR, d-ROMs, and the use of sodium-glucose cotransporter 2 inhibitors and calcium channel blockers. Because these glycemic parameters were correlated with each other, multiple stepwise regression analysis was performed. Multivariate stepwise regression analysis revealed that eGFR and HDL-C were inversely independently correlated with the serum PEDF level and that BMI, MAGE and UACR were positiviely independently correlated with the serum level of PEDF (Table 2).

\section{Relationship Between $\triangle$ PEDF and $\Delta$ clinical and Biochemical Variables}

The clinical characteristics of the 52 patients with T2DM for whom there was sufficient serum to perform the post-treatment analysis are shown in Table 3. After 24 weeks of treatment intervention, there was an observed improvement of CGM metrics, such as \%CV, MAGE, MODD, TIR, and MGL, and amelioration of glycemic and non-glycemic parameters, such as FPG, HbA1c, LDL-C, and TG. Serum PEDF levels tended to be decreased, but the effects of the 24-week treatment were not significant. As shown in Table 4 and Fig. 1, $\triangle$ MAGE $(r=0.36, p=0.009)$ and $\Delta \mathrm{d}-\mathrm{ROMs}(r=0.28$, $p=0.041)$ were positively associated with $\triangle \mathrm{PEDF}$.

\section{DISCUSSION}

An accumulating body of evidence has revealed the independent association of serum levels of PEDF with various types of cardiometabolic parameters, such as obesity, TG, reduced HDL$\mathrm{C}$, homeostasis model of insulin resistance (HOMA-IR), and decreased renal function in patients with high-risk for cardiovascular disease, including diabetic patients [7, 10-13, 3238]. Indeed, earlier studies, including our own, have shown that BMI, low HDL-C, and decreased eGFR evaluated by serum creatinine are independent correlates of serum PEDF levels in patients with T2DM $[12,28]$. Furthermore, serum levels of PEDF have been shown to be associated with the presence of microalbuminuria/albuminuria and to predict the development of microalbuminuria/albuminuria in patients with T2DM with normoalbuminuria and eGFR $>60 \mathrm{~mL} \mathrm{~min} / 1.73 \mathrm{~m}^{2}$ [36]. Cardiovascular complications are influenced by many factors other than glycemic control, and studies in a large number of diabetic subjects may be needed for the evaluation of the association between cardiometabolic factors and PEDF in multivariate analysis. However, the relationship between serum levels of PEDF and clinical variables that are associated with cardiometabolic disorders, including glucose variability and oxidative stress, in patients with T2DM remains unknown. To the best of our knowledge, there are no published reports that have examined the relationship between core CGM metrics and PEDF levels in patients with 
Table 1 Baseline clinical characteristics of the patients enrolled in study 1

\begin{tabular}{|c|c|}
\hline Clinical characteristics & Values \\
\hline Number & 124 \\
\hline Age (years) & $64.2 \pm 12.5$ \\
\hline Sex (male) & $78(62.9)$ \\
\hline Body mass index $\left(\mathrm{kg} / \mathrm{m}^{2}\right)$ & $26.0 \pm 4.6$ \\
\hline Smoking (\%) & $20(16.1)$ \\
\hline Duration of diabetes (years) & $13.5 \pm 11.4$ \\
\hline Hypertension & $84(67.7)$ \\
\hline Dyslipidemia & $94(75.8)$ \\
\hline \multicolumn{2}{|l|}{ Blood pressure $(\mathrm{mmHg})$} \\
\hline Systolic & $124.4 \pm 17.3$ \\
\hline Diastolic & $72.6 \pm 12.4$ \\
\hline Low-density lipoprotein cholesterol $(\mathrm{mg} / \mathrm{dL})$ & $103.0 \pm 33.6$ \\
\hline High-density lipoprotein cholesterol (mg/dL) & $47.4 \pm 15.5$ \\
\hline Triglycerides $(\mathrm{mg} / \mathrm{dL})$ & $136.5 \pm 82.7$ \\
\hline $\begin{array}{l}\text { Estimated glomerular filtration rate } \\
\qquad\left(\mathrm{mL} / \mathrm{min} / 1.73 \mathrm{~m}^{2}\right)\end{array}$ & $75.5 \pm 22.3$ \\
\hline Fasting plasma glucose $(\mathrm{mg} / \mathrm{dL})$ & $141.6 \pm 36.7$ \\
\hline Fasting C-peptide immunoreactivity $(\mathrm{ng} / \mathrm{mL})$ & $1.9 \pm 0.9$ \\
\hline The index CPR-IR & $15.5 \pm 8.0$ \\
\hline HbAlc (\%) & $8.3 \pm 1.6$ \\
\hline Mean glucose level (mg/dL) & $171.1 \pm 42.9$ \\
\hline \multicolumn{2}{|l|}{ Markers of glucose variability } \\
\hline$\% \mathrm{CV}$ & $23.5 \pm 6.2$ \\
\hline $\operatorname{MAGE}(\mathrm{mg} / \mathrm{dL})$ & $117.5 \pm 37.9$ \\
\hline MODD (mg/dL) & $29.2 \pm 12.8$ \\
\hline Time in range $(\%)$ & $60.6 \pm 29.3$ \\
\hline Time above range $(\%)$ & $38.3 \pm 30.2$ \\
\hline Time below range (\%) & $1.1 \pm 3.6$ \\
\hline UACR (mg/g Cre) & $192.8 \pm 542.2$ \\
\hline d-ROMs (U.CARR) & $344.6 \pm 60.9$ \\
\hline $\operatorname{PEDF}(\mu \mathrm{g} / \mathrm{mL})$ & $7.5 \pm 1.8$ \\
\hline Macroangiopathy & $29(23.4)$ \\
\hline Neuropathy & $70(56.5)$ \\
\hline Retinopathy & $47(37.9)$ \\
\hline Nephropathy & $55(44.4)$ \\
\hline
\end{tabular}

Table 1 continued

\begin{tabular}{ll}
\hline Clinical characteristics & Values \\
\hline Diabetes therapy & $7(5.6)$ \\
Diet alone & $36(29.0)$ \\
Metformin & $42(33.9)$ \\
Sulfonylureas & $3(2.4)$ \\
Glinides & $22(17.7)$ \\
$\alpha$-Glucosidase inhibitors & $18(14.5)$ \\
Thiazolidine & $51(41.1)$ \\
Dipeptidyl peptidase 4 inhibitors & $6(6.8)$ \\
Sodium-glucose cotransporter 2 inhibitors & $18(14.5)$ \\
Glucagon-like peptide 1 receptor agonists & $43(34.7)$ \\
Insulin & \\
Antihypertensive drugs & $53(42.7)$ \\
Angiotensin II receptor blockers & $51(41.1)$ \\
Calcium channel blockers & $14(11.3)$ \\
Diuretics & $4(3.2)$ \\
$\alpha$-Blockers & $16(12.9)$ \\
$\beta$-Blockers & $63(50.8)$ \\
Lipid-lowering drugs & $5(4.0)$ \\
Statins & \\
Fibrates & \\
\hline & \\
\hline &
\end{tabular}

Values in table are presented as the mean \pm standard deviation $(\mathrm{SD})$ or as a number with the percentage in parentheses

$C P R$-IR C-peptide immunoreactivity insulin resistance, $d$-ROMs diacron-reactive oxygen metabolites, $H b A l c$ glycated hemoglobin, $M A G E$ mean amplitude of glycemic excursion, $M O D D$ mean of daily differences, $P E D F$ pigment epithelium-derived factor, $\% C V$ coefficient of variation percentage, $U A C R$ urine albumin-to-creatinine ratio

T2DM. In this study, we found that in addition to these insulin resistance- and renal impairment-associated markers, MAGE derived from CGM was also independently correlated with serum levels of PEDF in patients with poorly controlled T2DM patients.

The clinical utility of CGM has been recently recognized due to improvements in accuracy and convenience [39]. CGM also provides clinically relevant and physiologically significant information as it can not only assess hyper- 
Table 2 Correlations of clinical variables with PEDF in study 1

\begin{tabular}{|c|c|c|c|c|}
\hline \multirow[t]{2}{*}{ Clinical and biochemical variables } & \multicolumn{2}{|c|}{$\begin{array}{l}\text { Univariate Spearman } \\
\text { correlation }\end{array}$} & \multicolumn{2}{|c|}{$\begin{array}{l}\text { Multivariate stepwise regression } \\
\text { analysis }\end{array}$} \\
\hline & $\overline{r_{\mathrm{s}}}$ & $p$ & $\bar{\beta}$ & $p$ \\
\hline Age (years) & -0.020 & 0.825 & & \\
\hline Sex & - & 0.132 & & \\
\hline Body mass index $\left(\mathrm{kg} / \mathrm{m}^{2}\right)$ & 0.373 & $<0.001$ & 0.235 & 0.006 \\
\hline Duration of diabetes (years) & 0.021 & 0.820 & & \\
\hline Systolic blood pressure $(\mathrm{mmHg})$ & 0.082 & 0.367 & & \\
\hline Diastolic blood pressure $(\mathrm{mmHg})$ & 0.072 & 0.427 & & \\
\hline Low-density lipoprotein cholesterol $(\mathrm{mg} / \mathrm{dL})$ & 0.086 & 0.340 & & \\
\hline High-density lipoprotein cholesterol $(\mathrm{mg} / \mathrm{dL})$ & -0.285 & 0.001 & -0.301 & 0.001 \\
\hline Triglycerides $(\mathrm{mg} / \mathrm{dL})$ & 0.308 & $<0.001$ & & \\
\hline Estimated glomerular filtration rate $\left(\mathrm{mL} / \mathrm{min} / 1.73 \mathrm{~m}^{2}\right)$ & -0.504 & $<0.001$ & -0.416 & $<0.001$ \\
\hline Fasting plasma glucose $(\mathrm{mg} / \mathrm{dL})$ & 0.138 & 0.127 & & \\
\hline Fasting C-peptide immunoreactivity (ng/mL) & 0.357 & $<0.001$ & & \\
\hline The index CPR-IR & 0.261 & 0.003 & & \\
\hline HbAlc (\%) & 0.088 & 0.332 & & \\
\hline Mean glucose level (mg/dL) & 0.151 & 0.095 & & \\
\hline$\% \mathrm{CV}$ & 0.172 & 0.055 & & \\
\hline $\operatorname{MAGE}(\mathrm{mg} / \mathrm{dL})$ & 0.200 & 0.026 & 0.202 & 0.015 \\
\hline $\operatorname{MODD}(\mathrm{mg} / \mathrm{dL})$ & 0.098 & 0.280 & & \\
\hline Time in range $(\%)$ & -0.161 & 0.074 & & \\
\hline Time above range (\%) & 0.172 & 0.057 & & \\
\hline Time below range (\%) & 0.135 & 0.135 & & \\
\hline UACR (mg/g Cre) & 0.363 & $<0.001$ & 0.192 & 0.023 \\
\hline d-ROMs (U.CARR) & 0.180 & 0.045 & & \\
\hline \multicolumn{5}{|l|}{ Diabetes therapy } \\
\hline Diet alone & - & 0.432 & & \\
\hline Metformin & - & 0.633 & & \\
\hline Sulfonylureas & - & 0.172 & & \\
\hline Glinides & - & 0.392 & & \\
\hline$\alpha$-Glucosidase inhibitors & - & 0.631 & & \\
\hline Thiazolidine & - & 0.829 & & \\
\hline Dipeptidyl peptidase 4 inhibitors & - & 0.865 & & \\
\hline
\end{tabular}


Table 2 continued

\begin{tabular}{|c|c|c|c|c|}
\hline \multirow[t]{2}{*}{ Clinical and biochemical variables } & \multicolumn{2}{|c|}{$\begin{array}{l}\text { Univariate Spearman } \\
\text { correlation }\end{array}$} & \multicolumn{2}{|c|}{$\begin{array}{l}\text { Multivariate stepwise regression } \\
\text { analysis }\end{array}$} \\
\hline & $r_{\mathrm{s}}$ & $p$ & $\bar{\beta}$ & $p$ \\
\hline Sodium-glucose cotransporter 2 inhibitors & - & 0.008 & & \\
\hline Glucagon-like peptide 1 receptor agonists & - & 0.340 & & \\
\hline Insulin & & 0.215 & & \\
\hline \multicolumn{5}{|l|}{ Antihypertensive drugs } \\
\hline Angiotensin II receptor blockers & - & 0.434 & & \\
\hline Calcium channel blockers & - & 0.036 & & \\
\hline Diuretics & - & 0.849 & & \\
\hline$\alpha$-Blockers & - & 0.119 & & \\
\hline$\beta$-Blockers & - & 0.770 & & \\
\hline \multicolumn{5}{|l|}{ Lipid-lowering drugs } \\
\hline Statins & - & 0.188 & & \\
\hline Fibrates & - & 0.167 & & \\
\hline$R^{2}$ & & & 0.452 & \\
\hline
\end{tabular}

Values represent Spearman's correlation coefficients. Between-group comparisons were tested by unpaired Mann-Whitney $U$ test

glycemia, MGL, and TIR, but also evaluate MAGE, MODD, and hypoglycemic unawareness [21-24]. Such information provided by CGM is of prognostic value because glucose variability and hypoglycaemia may be associated with future cardiovascular events in diabetes [40-46], which can not be evaluated by current clinical and scientific measures, such as hyperinsulinemic-euglycemic clamp and the oral glucose tolerance test. The importance of such information underlines our study of the relationship between CGM metrics and other clinical and biochemical markers, including oxidative stress and insulin resistance in patients with T2DM.

The results of our study show for the first time that MAGE, a marker of glucose variability, was one of the independent correlates of serum levels of PEDF in our study patients with T2DM. Furthermore, we found here that among various clinical and biochemical parameters, $\triangle \mathrm{MAGE}$ and $\Delta \mathrm{d}$-ROMs were positively associated with $\triangle \mathrm{PEDF}$ in study 2, thus suggesting that improvement of glucose variability and reduction of oxidative stress levels by anti-diabetic medications could be independently correlated with a decrease in serum PEDF levels. Therefore, although study 1 had a cross-sectional design and could not elucidate the causal relationship between MAGE and serum levels of PEDF in the 124 T2DM patients enrolled, the results do suggest that MAGE is not just a correlate, but rather may contribute to the elevation of serum PEDF levels in patients with T2DM. We have previously reported that amelioration of HOMA-IR, a marker of insulin resistance, by treatment with pioglitazone is independently correlated with a decrease in serum PEDF levels in patients with impaired glucose tolerance or T2DM [47]. Several clinical observations have shown associations between MAGE and markers 
Table 3 Clinical variables at baseline and after 24-weeks intervention in study 2

\begin{tabular}{|c|c|c|c|}
\hline \multirow[t]{2}{*}{ Clinical variables } & \multicolumn{2}{|l|}{ Values } & \multirow[t]{2}{*}{$p$} \\
\hline & Baseline & 24 weeks & \\
\hline Number of patients & 52 & 52 & - \\
\hline Age (years) & $64.8 \pm 10.9$ & $65.3 \pm 10.9$ & - \\
\hline Sex (male) & $38(73.1)$ & $38(73.1)$ & - \\
\hline Body mass index $\left(\mathrm{kg} / \mathrm{m}^{2}\right)$ & $25.8 \pm 4.6$ & $25.2 \pm 4.9$ & 0.518 \\
\hline Smoking (\%) & $8(15.4)$ & $8(15.4)$ & - \\
\hline Hypertension & $34(65.4)$ & $34(65.4)$ & - \\
\hline Dyslipidemia & $40(76.9)$ & $40(76.9)$ & - \\
\hline Systolic blood pressure $(\mathrm{mmHg})$ & $126.7 \pm 19.0$ & $133.3 \pm 23.0$ & 0.115 \\
\hline Diastolic blood pressure $(\mathrm{mmHg})$ & $71.6 \pm 12.8$ & $76.8 \pm 12.8$ & 0.044 \\
\hline Low-density lipoprotein cholesterol (mg/dL) & $96.9 \pm 30.8$ & $79.7 \pm 25.2$ & 0.002 \\
\hline High-density lipoprotein cholesterol (mg/dL) & $47.0 \pm 19.0$ & $48.5 \pm 14.4$ & 0.655 \\
\hline Triglycerides $(\mathrm{mg} / \mathrm{dL})$ & $120.5 \pm 63.5$ & $96.9 \pm 46.5$ & 0.033 \\
\hline Fasting plasma glucose $(\mathrm{mg} / \mathrm{dL})$ & $143.4 \pm 31.6$ & $125.9 \pm 29.6$ & 0.004 \\
\hline Fasting C-peptide immunoreactivity (ng/mL) & $1.9 \pm 0.8$ & $1.8 \pm 0.8$ & 0.750 \\
\hline The index CPR-IR & $14.6 \pm 6.7$ & $16.3 \pm 7.6$ & 0.245 \\
\hline HbAlc (\%) & $8.2 \pm 1.5$ & $6.9 \pm 0.9$ & $<0.001$ \\
\hline Mean glucose level $(\mathrm{mg} / \mathrm{dL})$ & $171.1 \pm 41.6$ & $141.0 \pm 29.7$ & $<0.001$ \\
\hline \multicolumn{4}{|l|}{ Markers of glucose variability } \\
\hline$\% \mathrm{CV}$ & $24.2 \pm 5.9$ & $22.2 \pm 6.7$ & 0.106 \\
\hline $\operatorname{MAGE}(\mathrm{mg} / \mathrm{dL})$ & $120.2 \pm 36.7$ & $94.3 \pm 34.2$ & $<0.001$ \\
\hline $\operatorname{MODD}(\mathrm{mg} / \mathrm{dL})$ & $30.9 \pm 10.7$ & $27.8 \pm 13.3$ & 0.014 \\
\hline Time in range $(\%)$ & $59.6 \pm 27.9$ & $81.4 \pm 20.1$ & $<0.001$ \\
\hline Time above range (\%) & $39.6 \pm 28.5$ & $17.1 \pm 20.3$ & $<0.001$ \\
\hline Time below range (\%) & $0.7 \pm 3.2$ & $1.5 \pm 3.7$ & 0.272 \\
\hline $\operatorname{PEDF}(\mu \mathrm{g} / \mathrm{mL})$ & $7.3 \pm 1.8$ & $7.1 \pm 1.9$ & 0.589 \\
\hline $\mathrm{UACR}$ (mg/g Cre) & $170.8 \pm 421.1$ & $200.8 \pm 471.5$ & 0.733 \\
\hline d-ROMs (U.CARR) & $344.0 \pm 66.3$ & $311.2 \pm 56.5$ & 0.008 \\
\hline Macroangiopathy & $14(26.9)$ & $14(26.9)$ & \\
\hline Neuropathy & $25(48.1)$ & $25(48.1)$ & - \\
\hline Retinopathy & $13(25.0)$ & $13(25.0)$ & - \\
\hline
\end{tabular}


Table 3 continued

\begin{tabular}{|c|c|c|c|}
\hline \multirow[t]{2}{*}{ Clinical variables } & \multicolumn{2}{|l|}{ Values } & \multirow[t]{2}{*}{$p$} \\
\hline & Baseline & 24 weeks & \\
\hline Nephropathy & $22(42.3)$ & $22(42.3)$ & - \\
\hline Diabetes therapy & $14(26.9)$ & $14(26.9)$ & - \\
\hline Diet alone & $7(13.5)$ & $0(0.0)$ & \\
\hline Metformin & $12(23.1)$ & $18(34.6)$ & \\
\hline Sulfonylureas & $14(26.9)$ & $3(5.8)$ & \\
\hline Glinides & $2(3.8)$ & $2(3.8)$ & \\
\hline$\alpha$-Glucosidase inhibitors & $8(15.4)$ & $13(25.0)$ & \\
\hline Thiazolidine & $3(5.8)$ & $7(13.5)$ & \\
\hline Dipeptidyl peptidase 4 inhibitors & $20(38.5)$ & $15(28.8)$ & \\
\hline Sodium glucose cotransporter 2 inhibitors & $2(3.8)$ & $6(11.5)$ & \\
\hline Glucagon-like peptide 1 receptor agonists & $6(11.5)$ & $15(28.8)$ & \\
\hline Insulin & $23(44.2)$ & $25(48.1)$ & \\
\hline Insulin dose of insulin therapy ( $U /$ day) & $20.8 \pm 11.4$ & $15.9 \pm 11.9$ & \\
\hline \multicolumn{4}{|l|}{ Medication } \\
\hline Angiotensin II receptor blockers & $16(30.8)$ & $22(42.3)$ & \\
\hline Calcium channel blockers & $21(40.4)$ & $20(38.5)$ & \\
\hline Diuretic & $6(11.5)$ & $8(15.4)$ & \\
\hline$\alpha$-Blockers & $2(3.8)$ & $1(1.9)$ & \\
\hline$\beta$-Blockers & $7(13.5)$ & $7(13.5)$ & \\
\hline Statins & $30(57.7)$ & $41(78.8)$ & \\
\hline
\end{tabular}

Values in table are presented as the mean \pm SD or as a number with the percentage in parentheses

of oxidative stress and increased risk for CVD [40-44, 48]. Although glucose variability, oxidative stress, and insulin resistance are interrelated with each other $[8,24,49,50]$, our present observations suggest that MAGE may be associated with serum levels of PEDF independently of oxidative stress and insulin resistance in T2DM patients.

The authors of numerous research and clinical papers have suggested that PEDF is functionally related to the development and progression of atherosclerotic cardiovascular disease $[7,8,51]$ and that its serum levels could be a biomarker of cardiovascular disease in high-risk patients, such as those with T2DM [19-21, 52-54]. We have previously shown that serum levels of PEDF are independently correlated with carotid artery intima-media thickness and vascular inflammation within the carotid atherosclerotic plaques, two representative indicators of atherosclerosis that could predict future cardiovascular events in humans $[19,55]$. 
Table 4 Correlation of change in clinical variables with change in PEDF in study 2

\begin{tabular}{|c|c|c|}
\hline Clinical variables (change) & $r$ & $p$ \\
\hline$\Delta$ Systolic blood pressure $(\mathrm{mmHg})$ & -0.032 & 0.821 \\
\hline$\Delta$ Diastolic blood pressure $(\mathrm{mmHg})$ & -0.031 & 0.825 \\
\hline$\Delta$ Low-density lipoprotein cholesterol $(\mathrm{mg} / \mathrm{dL})$ & 0.031 & 0.827 \\
\hline$\Delta$ High-density lipoprotein cholesterol $(\mathrm{mg} / \mathrm{dL})$ & 0.048 & 0.734 \\
\hline$\Delta$ Triglycerides $(\mathrm{mg} / \mathrm{dL})$ & 0.186 & 0.186 \\
\hline$\Delta$ Fasting plasma glucose state $(\mathrm{mg} / \mathrm{dL})$ & 0.240 & 0.087 \\
\hline$\Delta$ Fasting C-peptide immunoreactivity $(\mathrm{ng} / \mathrm{mL})$ & -0.001 & 0.996 \\
\hline$\Delta$ The index CPR-IR & -0.204 & 0.146 \\
\hline$\Delta \mathrm{HbAlc}(\%)$ & 0.111 & 0.435 \\
\hline$\Delta$ Mean glucose level $(\mathrm{mg} / \mathrm{dL})$ & 0.179 & 0.204 \\
\hline$\Delta \% \mathrm{CV}$ & 0.091 & 0.523 \\
\hline$\triangle \mathrm{MAGE}(\mathrm{mg} / \mathrm{dL})$ & 0.360 & 0.009 \\
\hline$\Delta \mathrm{MODD}(\mathrm{mg} / \mathrm{dL})$ & 0.218 & 0.120 \\
\hline$\Delta$ Time in range $(\%)$ & -0.200 & 0.151 \\
\hline$\Delta$ Time above range $(\%)$ & 0.182 & 0.196 \\
\hline$\Delta$ Time below range $(\%)$ & -0.015 & 0.914 \\
\hline$\Delta \mathrm{UACR}(\mathrm{mg} / \mathrm{g} \mathrm{Cre})$ & 0.105 & 0.468 \\
\hline$\Delta$ d-ROMs (U.CARR) & 0.284 & 0.041 \\
\hline
\end{tabular}

Abbreviations are the same as in Table 1

Furthermore, serum PEDF levels are also associated with vulnerable plaques within the coronary arteries and could predict necrotic core progression in patients who undergo percutaneous coronary intervention [20, 52-54]. There is a growing body of evidence showing that MAGE is associated with endothelial dysfunction and severity of coronary artery disease and that it could be a predictor of future cardiovascular events in patients with T2DM [40-44]. Therefore, the clinical association between serum levels of PEDF and atherosclerotic cardiovascular disease may be partly ascribed to the elevation of MAGE in T2DM patients.

In this study, although the significant correlation between d-ROMs and serum PEDF was lost in the multiple stepwise regression analysis,
$\Delta$ d-ROMs change was positively associated with $\triangle \mathrm{PEDF}$ in patients with T2DM in study 2 . Glucose variability indicated by the increase in MAGE is associated with oxidative stress levels, such as d-ROMs [24, 45]. Moreover, PEDF has been shown to have anti-oxidative and insulinsensitizing properties in both cell culture and animal models $[7,8,56]$, and its secretion from adipocytes and liver is increased under oxidative stress conditions [57, 58]. These observations suggest that serum levels of PEDF may be elevated as a counter-system against MAGE-induced oxidative stress generation in patients with T2DM. Given the role of oxidative stress in insulin resistance and diabetic nephropathy $[59,60]$, oxidative stress may partly contribute to the clinical link between serum levels of PEDF levels and markers of insulin resistance 


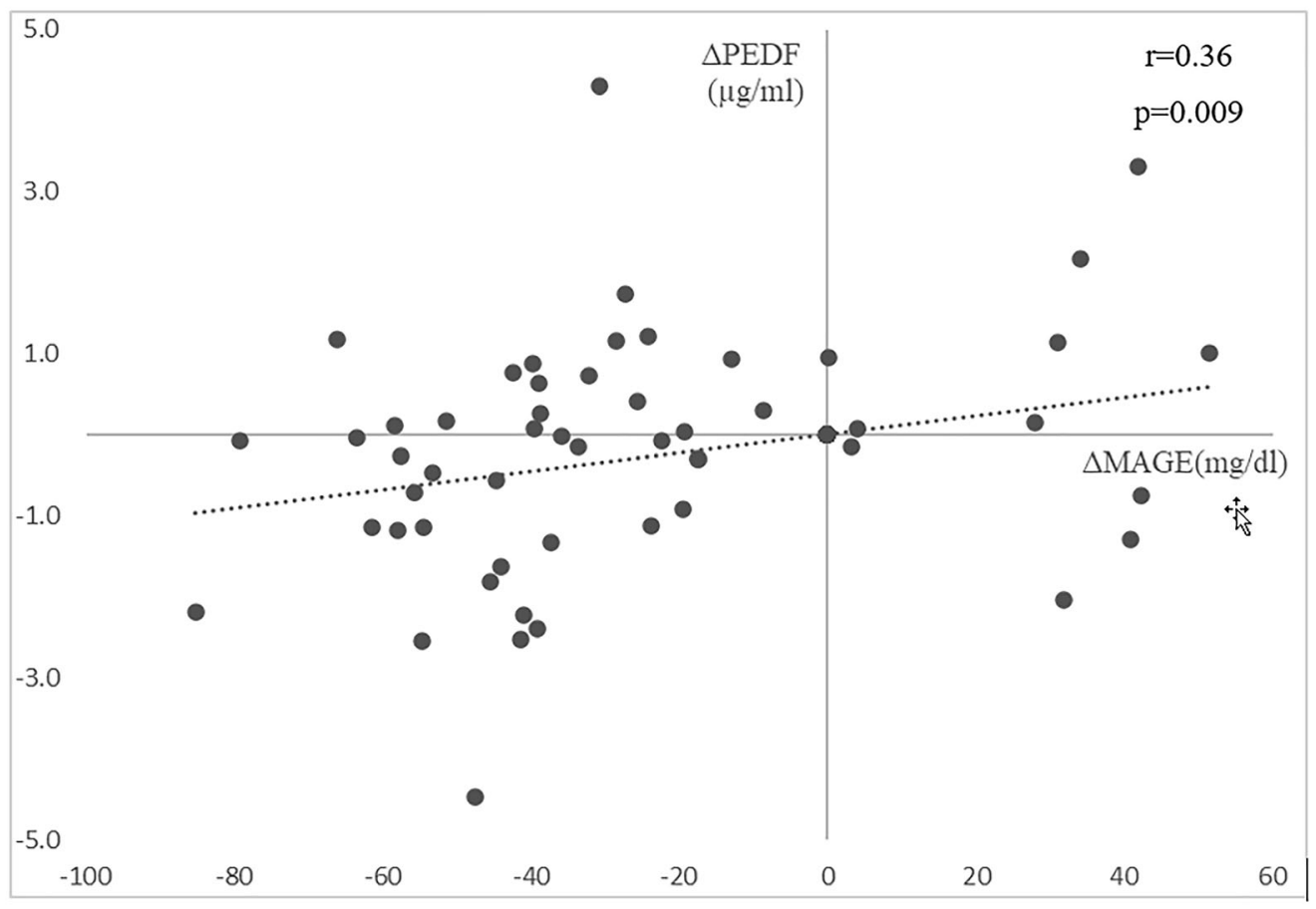

Fig. 1 Correlation between change in mean amplitude of glycemic excursion $(\triangle M A G E)$ and change in pigment epitheliumderived factor $(\triangle P E D F)$

and/or renal impairment in patients with T2DM.

The present study has several limitations. First, prior studies have shown that PEDF is increased with obesity and varies with the amount of body fat $[7,8]$. However, in the current study, the only index of obesity presented is BMI. The lack of other measures, such as waist circumference or body composition, is a limitation in this study. Second, there is no control group without diabetes; thus, there is no reference range for any of key variables, especially PEDF. The design also prevents an understanding of the overlap of PEDF concentration among people with and without T2DM. Therefore, this study does not show how sensitive or specific PEDF is as a biomarker for diabetes. Third, although almost all of the participants in study 1 were already taking medications for T2DM, these were not sufficient to achieve glycemic control; the mean HbA1c value was $8.3 \%$. Intervention was performed as part of study 2 in poorly controlled T2DM patients. Our present findings may not be generalizable to other patient groups. Moreover, these are real-world observational studies and even study 2 was not an interventional study in the true sense of clinical research. Multiple drugs were used and adjusted during the intervention, which may limit the pure role of glucose-lowering effects on PEDF. In addition, we did not know the exact reason for the apparent lack of PEDF changes in study 2 as a whole even though HbA1c, TIR, MAGE, and d-ROMs were all improved. Fourth, in this study, we did not examine the relationship between PEDF and some clear clinical variables related to cardiovascular events, such as blood pressure variability. Fifth, although drug medication was not associated with serum levels of PEDF in the multivariate analysis, we can not totally exclude the possibility that several drugs, such as sympathetic agents and sodium-glucose cotransporter 2 inhibitors, could affect the present findings. [17] Sixth, we calculated MODD by measuring glucose levels continuously only for 2 days, and thus it may not be a reliable measure of inter-day glycemic variability. However, 
we have previously shown that decreases in MODD for 2 days after anti-hyperglycemic agents are independently associated with a reduction in d-ROMs in patients with T2DM [24].

\section{CONCLUSIONS}

In conclusion, this is the first study to demonstrate that serum levels of PEDF are independently correlated with MAGE in patients with T2DM and that amelioration of glucose variability and oxidative stress is associated with a reduction in serum PEDF level. This study was an exploratory analysis, and any findings require careful follow-up in order to determine the causation. Accordingly, a further longitudinal study is needed to clarify whether serum levels of PEDF may be a biomarker and therapeutic target for cardiovascular disease in patients with T2DM, especially those with high glucose variability.

\section{ACKNOWLEDGEMENTS}

We thank the participants of the study. Furthermore, we thank Yasue Moroto of the Showa University School of Medicine for clinical support.

Funding. This study was supported in part by Grants-in-Aid for Scientific Research (Grant number: 17K08968) from the Ministry of Education, Culture, Sports, Science and Technology, Tokyo, Japan (to S.Y.).

Authorship. All named authors meet the International Committee of Medical Journal Editors (ICMJE) criteria for authorship for this article, take responsibility for the integrity of the work as a whole, and have given their approval for this version to be published.

Authorship Contributions. MO contributed to study design, data acquisition, and data analysis and wrote the manuscript. TF, YM, TF, and SY reviewed and edited the manuscript for intellectual content. MO and SY drafted the manuscript. TF, MO, YK, HN, AF, NO, HY, NS, HK, KS, YT, MH, MT, YM, TF, TM, TH, and SY interpreted data and critically revised and wrote the manuscript. All authors read and approved the final version of the manuscript.

Disclosures. The authors of this manuscript have the following competing interests: Shoichi Yamagishi received lecture fees from Ono Pharmaceutical Co. LTD, Sanofi K.K., Lilly, and Boehringer Ingelheim. Tomoki Fujikawa, Makoto Ohara, Yo Kohata, Hiroe Nagaike, Ayako Fukase, Naoya Osaka, Hironori Yashima, Nobuko Sato, Hideki Kushima, Kyoko Shinmura, Yasuyoshi Takahashi, Munenori Hiromura, Michishige Terasaki, Yusaku Mori, Tomoyasu Fukui, Takanori Matsui, and Tsutomu Hirano have nothing to disclose.

Compliance with Ethics Guidelines. This study complies with the principles laid in the Declaration of Helsinki. The study protocol was approved by the ethics committee of the Showa University School of Medicine (permission no. 3099). Informed consent was obtained from all individual participants included in the study by the opt-out method, as shown on our hospital website and the poster at Showa University Hospital. Subjects could opt out of the study at any time.

Data Availability. The datasets generated during and/or analyzed during the current study are available from the corresponding author on reasonable request.

Open Access. This article is licensed under a Creative Commons Attribution-NonCommercial 4.0 International License, which permits any non-commercial use, sharing, adaptation, distribution and reproduction in any medium or format, as long as you give appropriate credit to the original author(s) and the source, provide a link to the Creative Commons licence, and indicate if changes were made. The images or other third party material in this article are included in the article's Creative Commons licence, unless indicated otherwise in a credit line to the material. If material is not included in the article's Creative Commons licence and 
your intended use is not permitted by statutory regulation or exceeds the permitted use, you will need to obtain permission directly from the copyright holder. To view a copy of this licence, visit http://creativecommons.org/licenses/by$\mathrm{nc} / 4.0 /$.

\section{REFERENCES}

1. Tombran-Tink J, Chader GG, Johnson LV. PEDF: pigment epithelium-derived factor with potent neuronal differentiative activity. Exp Eye Res. 2019;53:411-4.

2. Tombran-Tink J, Barnstable CJ. PEDF: a multifaceted neurotrophic factor. Nat Rev Neurosci. 2003;4:628-36.

3. Dawson DW, Volpert OV, Gillis P, et al. Pigment epithelium-derived factor: a potent inhibitor of angiogenesis. Science. 1999;285:245-8.

4. Yamagishi S, Matsui T, Nakamura K, Ueda S, Noda Y, Imaizumi T. Pigment epithelium-derived factor (PEDF): its potential therapeutic implication in diabetic vascular complications. Curr Drug Targets. 2008;9:1025-9.

5. Yamagishi SI, Koga Y, Sotokawauchi A, et al. Therapeutic potential of pigment epithelium-derived factor in cancer. Curr Pharm Des. 2019;25:313-24.

6. Famulla S, Lamers D, Hartwig S, et al. Pigment epithelium-derived factor (PEDF) is one of the most abundant proteins secreted by human adipocytes and induces insulin resistance and inflammatory signaling in muscle and fat cells. Int $\mathrm{J}$ Obes. 2011;35:762-72.

7. Yamagishi SI, Matsui T. Pigment epitheliumderived factor: a novel therapeutic target for cardiometabolic diseases and related complications. Curr Med Chem. 2018;25:1480-500.

8. Yamagishi SI, Matsui T. Anti-atherothrombogenic properties of PEDF. Curr Mol Med. 2010;10:284-91.

9. Brook N, Brook E, Dharmarajan A, Chan A, Dass CR. The role of pigment epithelium-derived factor in protecting against cellular stress. Free Radic Res. 2019;53:1166-80.

10. Yamagishi S, Adachi $\mathrm{H}$, Abe A, et al. Elevated serum levels of pigment epithelium-derived factor in the metabolic syndrome. J Clin Endocrinol Metab. 2006;91:2447-50.
11. Jenkins A, Zhang SX, Gosmanova A, et al. Increased serum pigment epithelium derived factor levels in type 2 diabetes patients. Diabetes Res Clin Pract. 2008;82:e5-7.

12. Nakamura K, Yamagishi S, Adachi H, Kurita-Nakamura Y, Matsui T, Inoue H. Serum levels of pigment epithelium-derived factor (PEDF) are positively associated with visceral adiposity in Japanese patients with type 2 diabetes. Diabetes Metab Res Rev. 2009;25:52-6.

13. Li TH, Qiu CJ, Yu XJ, Liu DD, Zhou PF, Wu L. Increased serum pigment epithelium-derived factor in women with gestational diabetes is associated with type 2 diabetes. Int J Endocrinol. 2015;2015: 346938.

14. Crowe $\mathrm{S}, \mathrm{Wu} \mathrm{LE}$, Economou $\mathrm{C}$, et al. A hyperinsulinemic-euglycemic clamp study. Cell Metab. 2009;10:40-7.

15. Toloza FJK, Pérez-Matos MC, Ricardo-Silgado ML, et al. Comparison of plasma pigment epitheliumderived factor (PEDF), retinol binding protein 4 (RBP-4), chitinase-3-like protein 1 (YKL-40) and brain-derived neurotrophic factor (BDNF) for the identification of insulin resistance. J Diabetes Complicat. 2017;31:1423-9.

16. Joham AE, Teede HJ, Hutchison SK, et al. Pigment epithelium-derived factor, insulin sensitivity, and adiposity in polycystic ovary syndrome: impact of exercise training. Obesity (Silver Spring). 2012;20: 2390-6.

17. Lashbrook BL, Steinle JJ. Beta-adrenergic receptor regulation of pigment epithelial-derived factor expression in rat retina. Auton Neurosci. 2005;121: 33-9.

18. Nakamura K, Yamagishi S, Adachi H, et al. Serum level of pigment epithelium derived factor (PEDF) is an independent determinant of resting heart rate in Japanese subjects. Int J Cardiol. 2009;136:245-7.

19. Tahara N, Yamagishi SI, Tahara A, et al. Serum level of pigment epithelium-derived factor is a marker of atherosclerosis in humans. Atherosclerosis. 2011;219:311-5.

20. Iwata A, Miura S, Morii J, Yamagishi SI, Saku K. Association between plasma pigment epitheliumderived factor levels and tissue characteristics of coronary plaque using integrated backscatter intravascular ultrasound. Intern Med. 2011;50: 1889-94.

21. Shiga Y, Miura S, Mitsutake R, Yamagishi S, Saku K. Significance of plasma levels of pigment epithelium-derived factor as determined by multidetector row computed tomography in patients with mild 
chronic kidney disease and/or coronary artery disease. J Int Med Res. 2011;39:880-90.

22. Ajjan R, Slattery D, Wright E. Continuous glucose monitoring: a brief review for primary care practitioners. Adv Ther. 2019;36:579-96.

23. Chehregosha H, Khamseh ME, Malek M, Hosseinpanah F, Ismail-Beigi F. A view beyond HbA1c: role of continuous glucose monitoring. Diabetes Ther. 2019;10:853-63.

24. Ohara M, Fukui T, Ouchi M, et al. Relationship between daily and day-to-day glycemic variability and increased oxidative stress in type 2 diabetes. Diabetes Res Clin Pract. 2016;122:62-70.

25. Cockcroft DW, Gault MH. Prediction of creatinine clearance from serum creatine. Nephron. 1976;16: $31-41$.

26. Araki E, Haneda M, Kasuga M, et al. New glycemic targets for patients with diabetes from the Japan Diabetes Society. J Diabetes Investig. 2017;8:123-5.

27. Czerwoniuk D, Fendler W, Walenciak L, Mlynarski W. GlyCulator: a glycemic variability calculation tool for continuous glucose monitoring data. J Diabetes Sci Technol. 2011;5:447-51.

28. Ohara M, Nagaike $H$, Goto S, et al. Improvements of ambient hyperglycemia and glycemic variability are associated with reduction in oxidative stress for patients with type 2 diabetes. Diabetes Res Clin Pract. 2018;139:253-61.

29. Fukami K, Yamagishi S, Okuda S. Development of enzyme-linked immunosorbent assay system for PEDF and its clinical utility. Curr Mol Med. 2010;10:317-20.

30. Okura T, Nakamura R, Fujioka Y, et al. CPR-IR is an insulin resistance index that is minimally affected by hepatic insulin clearance-a preliminary research. PLoS One. 2018;13:e0197663.

31. Kohata $\mathrm{Y}$, Ohara M, Nagaike H, et al. Association of hemoglobin A1c, 1,5-anhydro-D-glucitol and glycated albumin with oxidative stress in type 2 diabetes mellitus patients: a cross-sectional study. Diabetes Ther. 2020;11:655-65.

32. Pek S, Tavintharan S, Woon K, Niyati J, Lim SC, Sum CF. Associations between pigment epitheliumderived factor, insulin resistance and high density lipoprotein. Diabet Med. 2013;30:1067-74.

33. Arimura T, Miura S, Sugihara M, Iwata A, Yamagishi S, Saku K, Cardiol J. Association between plasma levels of pigment epithelium-derived factor and renal dysfunction in patients with coronary artery disease. Cardiol J. 2011;18:515-20.
34. Motomiya Y, Yamagishi S, Adachi H, Abe A. Increased serum concentrations of pigment epithelium-derived factor in patients with endstage renal disease. Clin Chem. 2006;52:1970-1.

35. Jenkins AJ, Zhang SX, Rowley KG, et al. Increased serum pigment epithelium-derived factor is associated with microvascular complications, vascular stiffness and inflammation in Type 1 diabetes. Diabet Med. 2007;24:1345-51.

36. Hui E, Yeung CY, Lee PC, et al. Elevated circulating pigment epithelium-derived factor predicts the progression of diabetic nephropathy in patients with type 2 diabetes. J Clin Endocrinol Metab. 2014;99:E2169-2177.

37. Tahara N, Yamagishi S, Kodama N, et al. Clinical and biochemical factors associated with area and metabolic activity in the visceral and subcutaneous adipose tissues by FDG-PET/CT. J Clin Endocrinol Metab. 2015;100:E739-747.

38. Hunt KJ, Jenkins AJ, Fu D, et al. Serum pigment epithelium-derived factor: Relationships with cardiovascular events, renal dysfunction, and mortality in the Veterans Affairs Diabetes Trial (VADT) cohort. J Diabetes Complications. 2019;33:107410.

39. American Diabetes Association. 7. Diabetes technology: standards of medical care in diabetes-2020. Diabetes Care. 2020;2020(43):S77-88.

40. Su G, Mi S, Tao H, et al. Association of glycemic variability and the presence and severity of coronary artery disease in patients with type 2 diabetes. Cardiovasc Diabetol. 2011;10:19.

41. Mi SH, Su G, Li Z, et al. Comparison of glycemic variability and glycated hemoglobin as risk factors of coronary artery disease in patients with undiagnosed diabetes. Chin Med J (Engl). 2012;125:38-43.

42. Zhang JW, He LJ, Cao SJ, Yang Q, Yang SW, Zhou YJ. Effect of glycemic variability on short term prognosis in acute myocardial infarction subjects undergoing primary percutaneous coronary interventions. Diabetol Metab Syndr. 2014;6:76.

43. Tong L, Chi C, Zhang Z. Association of various glycemic variability indices and vascular outcomes in type- 2 diabetes patients: a retrospective study. Medicine (Baltimore). 2018;97:e10860.

44. Benalia M, Zeller M, Mouhat B, et al. Glycaemic variability is associated with severity of coronary artery disease in patients with poorly controlled type 2 diabetes and acute myocardial infarction. Diabetes Metab. 2019;45:446-52.

45. Khunti K, Davies M, Majeed A, et al. Hypoglycemia and risk of cardiovascular disease and all-cause 
mortality in insulin-treated people with type 1 and type 2 diabetes: a cohort study. Diabetes Care. 2015;38:316-22.

46. Otowa-Suematsu N, Sakaguchi K, Komada H, et al. Comparison of the relationship between multiple parameters of glycemic variability and coronary plaque vulnerability assessed by virtual histologyintravascular ultrasound. J Diabetes Investig. 2017;9:610-5.

47. Tahara N, Matsui T, Yamagishi S. Change in serum PEDF level after pioglitazone treatment is independently correlated with that in HOMA-IR. Int J Cardiol. 2014;172:244-6.

48. Quagliaro L, Piconi L, Assaloni R, et al. Intermittent high glucose enhances apoptosis related to oxidative stress in human umbilical vein endothelial cells: the role of protein kinase $\mathrm{C}$ and $\mathrm{NAD}(\mathrm{P}) \mathrm{H}-$ oxidase activation. Diabetes. 2003;52:2795-804.

49. Monnier L, Colette C, Owens DR. Integrating glycaemic variability in the glycaemic disorders of type 2 diabetes: a move towards a unified glucose tetrad concept. Diabetes Metab Res Rev. 2009;25:393-402.

50. Meigs JB, Larson MG, Fox CS, et al. Association of oxidative stress, insulin resistance, and diabetes risk phenotypes: the Framingham Offspring Study. Diabetes Care. 2007;30:2529-35.

51. Ma S, Wang S, Li M, Zhang Y, Zhu P. The effects of pigment epithelium-derived factor on atherosclerosis: putative mechanisms of the process. Lipids Health Dis. 2018;17:240.

52. Wang F, Ma X, Zhou M, et al. Serum pigment epithelium-derived factor levels are independently correlated with the presence of coronary artery disease. Cardiovasc Diabetol. 2013;12:56.
53. Gardner AW, Parker DE, Montgomery PS, et al. Influence of diabetes on ambulation and inflammation in men and women with symptomatic peripheral artery disease. J Clin Transl Endocrinol. 2015;2:137-43.

54. Nozue T, Yamagishi S, Hirano T, et al. Pigment epithelium-derived factor is associated with necrotic core progression during statin therapy. Coron Artery Dis. 2015;26:107-13.

55. Tahara N, Tahara A, Honda A, et al. Molecular imaging of vascular inflammation. Curr Pharm Des. 2014;20:2439-47.

56. Matsui T, Nishino Y, Ojima A, Maeda S, Tahara N, Yamagishi SI. Pigment epithelium-derived factor improves metabolic derangements and ameliorates dysregulation of adipocytokines in obese type 2 diabetic rats. Am J Pathol. 2014;184:1094-103.

57. Nakamura K, Yamagishi S, Yoshida T, et al. Hydrogen peroxide stimulates pigment epitheliumderived factor gene and protein expression in the human hepatocyte cell line OUMS-29. J Int Med Res. 2007;35:427-32.

58. Yamagishi S, Matsui T, Adachi H, Takeuchi M. Positive association of circulating levels of advanced glycation end products (AGEs) with pigment epithelium-derived factor (PEDF) in a general population. Pharmacol Res. 2010;61:103-7.

59. Biobaku F, Ghanim H, Batra M, Dandona P. Macronutrient-mediated inflammation and oxidative stress: relevance to insulin resistance, obesity, and atherogenesis. J Clin Endocrinol Metab. 2019;104:6118-28.

60. Yamagishi S, Matsui T. Advanced glycation end products, oxidative stress and diabetic nephropathy. Oxid Med Cell Longev. 2010;3:101-8. 